\title{
TRÂNSITO COMO TEMÁTICA INTERDISCIPLINAR EM PROMOÇÃO DA SAÚDE
}

\author{
TRAFFIC AS AN INTERDISCIPLINARY THEME IN HEALTH PROMOTION
}

\author{
Anselmo Cordeiro de Souza \\ Maria Cecília Leite de Moraes $^{2}$ \\ Leonardo Tavares Martins ${ }^{3}$ \\ Morenilza Bezerra de Conceição Fróes ${ }^{4}$ \\ Elaine dos Santos Salzano ${ }^{5}$ \\ Myrian Regazzo de Jesus Moura ${ }^{6}$ \\ Recebido em: 05 jun. 2017 \\ Aceito em: 20 jun. 2018
}

RESUMO: O tráfego e a circulação humanos são, hoje, prioridades nas agendas políticas mundial e nacional, pelo impacto social de sua articulação e por conta da operacionalização, expressos em estatísticas epidemiológicas, criminais e ambientais, e no contexto das demandas logísticas de apropriação do espaço urbano. Este artigo objetiva explicitar a proposição interdisciplinar aplicada ao trânsito como mecanismo de produção de conhecimento, soluções e práticas melhores e mais efetivas. Trata-se de um ensaio teórico, que se limita a uma abordagem bibliográfica e narrativa, tendo como articulador um conceito nuclear em promoção da saúde, ou seja, o "saudável". A partir da literatura consultada, confirmou-se a possibilidade da interdisciplinaridade como estratégia para superar as fortes tensões presentes na temática do trânsito. Isto significa uma valorização da vida e da saúde, por meio de uma estrutura congruente, ambientada na convivência e na relação fraterna, mediadas pelo trânsito como veículo de acesso e estreitamento das relações e dos laços humanos (físicos ou subjetivos), intencionando o bem-estar e a qualidade de vida social. A discussão a respeito do tema contribuiu para um clareamento e uma reflexão sobre a escandalosa necessidade de novos caminhos, baseados em propostas integradoras.

Palavras-chave: Pesquisa interdisciplinar. Acidentes de Trânsito. Promoção da Saúde. Organização e administração.

ABSTRACT: Human traffic and circulation are now priority in the national and international political agendas, due to the social impact of its articulation and operationalization expressed in epidemiological, criminal and environmental statistics,

\footnotetext{
1 Instrutor de Trânsito do DETRAN/SP. Possui Licenciatura em Pedagogia pela Faculdade da Aldeia de Carapicuíba (FALC). Bacharelado em Teologia pelo Seminário Adventista Latino-Americano de Teologia (SALT). Pós-Graduado em Gestão de Pessoas e Mestre em Promoção da Saúde, pelo Centro Universitário Adventista de São Paulo (UNASP).

2 Terapeuta Ocupacional. Mestra e Doutora em Saúde Pública pela Universidade de São Paulo (USP). Docente do Mestrado Profissional em Promoção da Saúde do Centro Universitário Adventista de São Paulo (UNASP).

${ }^{3}$ Profissional de Educação Física. Doutor em Educação pela Universidade Estadual de Campinas (Unicamp). Docente do Mestrado Profissional em Promoção da Saúde do Centro Universitário Adventista de São Paulo (UNASP).

${ }^{4}$ Enfermeira. Especialista em Ortotrauma. Mestranda em Promoção da Saúde pelo Centro Universitário Advenstista de São Paulo (UNASP).

${ }^{5}$ Instrutora de Trânsito de DETRAN/SP. Licenciada em Pedagogia pela Faculdade da Aldeia de Carapicuiba (FALC).

6 Instrutora de Trânsito do DETRAN/SP. Psicóloga. Coordenadora da Graduação em Tecnologia em Transportes da Faculdade Zumbi dos Palmares.
} 
and in the context of the logistic demands of urban space appropriation. This article aimed to explain the interdisciplinary proposition applied to traffic, as mechanism of production of knowledge, solutions and better and more effective practices. This is a theoretical essay limited to a bibliographical and narrative approach, which takes the concept of health promotion, namely "healthy", as articulator. From the literature consulted, we confirmed the possibility of the interdisciplinarity as a strategy to overcome the strong tensions present in the thematic traffic. It means that there is a valuation of life and health through a congruent structure, set in the coexistence and fraternal relationship, mediated by traffic as a vehicle of access and narrowing of human relations and ties (physical or subjective), intending the well-being and quality of social life. The discussion on the subject contributed to a clarification and reflection of the scandalous need for new paths based on an integrative proposal.

Keywords: Interdisciplinary research. Accidents, Traffic; Health Promotion; Organization and Administration.

\section{INTRODUÇÃO}

A mobilidade e a circulação humana atualmente constituem prioridades na agenda social, tanto em termos da política nacional como da mundial, o que pode ser notado pelas recorrentes menções ao tema nos âmbitos da saúde, da educação, da infraestrutura, da segurança pública, do meio ambiente, entre outros. A temática também se faz sempre presente em relatórios periódicos da Organização Mundial da Saúde (OMS) (WHO, 2004; BRASIL, 2014A; BACCHIERI, BARROS, 2011).

O debate sobre trânsito tem tradicionalmente sido abordado nas áreas da Engenharia, com foco na infraestrutura e na gestão; do Direito, considerando as relações e os ordenamentos jurídicos; e da Educação. Nas ciências da saúde, é particularmente estudado na Psicologia (HADDAD et al., 2010; SILVA, GUNTHER, 2009) e, recentemente, na saúde pública, em espaço de reflexão acadêmica e científica sobre promoção da saúde (SOUZA et al., 2016; BRASIL, 2014c).

A promoção da saúde é classicamente definida como um processo de capacitação social e individual, para atuar na melhoria de sua saúde e qualidade de vida, em ambiente de corresponsabilização entre os atores sociais (BUSS et al., 2009; ABDALA et al., 2015). "Neste sentido aponta-se o construto 'saudável', como nuclear nos objetivos fins de ações promotoras de saúde, pautando-se como importante articulador de natureza intersetorial (AZEVEDO et al., 2012; BUSS et al., 2009). Este referencial contempla o trânsito e a mobilidade urbana.

No Brasil, os acidentes de trânsito são apontados como a maior causa de morte entre jovens e adultos, potencializada pelo crescimento urbano, o que torna o fenômeno 'trânsito' elemento de preocupação na gestão urbana - inclusive no que se refere à sensação de (in)segurança em meio ao tráfego urbano. Configura-se, assim, um problema de caráter social, político, econômico e cultural (MASSAÚ, ROSA, 2016; SILVA, 2016, REICHENHEIM et al., 2011). 
Este contexto delineia-se com ainda mais clareza ao se vislumbrar o impacto social da articulação e da operacionalização de dados relativos ao trânsito, expressos em estatísticas epidemiológicas e indicados pelos Acidentes de Trânsito Terrestre (ATT) (MINAYO, 2012), criminais (verificados pelo número de processos e detenções relacionados a crimes de trânsito) (MARTINS, 2010) e ambientais (verificados por fatores relacionados ao bem-estar). Isto para não mencionar a reponsabilidade social e ecológica em relação aos recursos naturais e sua sustentabilidade (COSTA, 2003).

É também relevante o impacto econômico causado pelas discrepâncias, ou efeitos colaterais, nos diversos espaços e dimensões que compõem o trânsito como tal (SILVA et al., 2015). Sem negligenciar referência da temática como variável importante no contexto das demandas logísticas de apropriação do espaço urbano, e a gestão de sua operacionalização (COSTA, 2003). Os números avolumam-se, e são conhecidos e exaustivamente divulgados pelos meios de comunicação em massa, sendo inclusive redundante mencioná-los aqui.

Deste modo, o tráfego humano, em seus desdobramentos em uma realidade complexa, enquanto suas concepções estrutural, funcional ou organizacional, revela-se um desafio quando se parte em busca de suas melhores e mais efetivas práticas. Para tal enfrentamento, pode ser conveniente uma abordagem interdisciplinar, na qual atores variados dialoguem e produzam estratégias conjugadas para implementação de ações intersetoriais, em uma parceria indissociável (AZEVEDO et al., 2012; MINAYO, 2012; VIEIRA et al., 2010).

A temática trânsito emerge como um construto polissêmico em desenvolvimento e ainda busca maior clareza para seus pressupostos, caminhos metodológicos e produção de conhecimento. Neste caminho, a apropriação de uma ou outra abordagem acadêmica deve sempre ser coerente com convalidações ontológicas e epistemológicas (HOFFMANN et al., 2003). Neste sentido nosso maior esforço, sendo este resultado de exercício reflexivo introdutório, é manter a coerência das pontuações feitas neste trabalho, bem como da própria consistência do mesmo, não obstante atentos a atual inclinação dos caminhos da pesquisa acadêmica e cientifica do trânsito.

Nossa intenção neste artigo não se dá em uma exposição exaustiva da temática trânsito, ou mesmo pretende trazer a conciliação de todos os conflitos, incongruências ou descompassos presentes em muitos dos desdobramentos da temática, mas antes nos limitamos a tentativa de explicitar a discussão a respeito do tema a partir de dispositivos normativos e legais, da literatura acadêmico cientifica clássica e atual de interesse, no intuito de que ao evidenciar a reflexão em tais elaborações possamos contribuir numa melhor elucidação da temática.

Este artigo objetivou expor as nuances de uma possível proposição interdisciplinar do trânsito, como mecanismo de produção de conhecimento, soluções e práticas melhores e mais efetivas. 


\section{MÉTODO}

Trata-se de um ensaio teórico de abordagem bibliográfica de caráter narrativo (ROTHER, 2007; VOSGERAU, ROMANOWSKI, 2014). As buscas das produções científicas realizaram-se numa das principais bases de indexação de artigos de acesso aberto e de cobertura regional (PARKER et al., 2014), a saber, o Scientific Electronic Library Online (SciELO); e no buscador Google Scholar (GS), fonte de busca que têm se projetado como uma das principais formas de resgate de artigos científicos mostrando-se muito útil, devido à sua simplicidade, rapidez e amplitude de informação (PUCCINI et al., 2015). Realizadas no período de outubro de 2015 a outubro de 2016, por meio da combinação dos descritores em português "trânsito", "interdisciplinaridade", "sustentabilidade", "saudável" utilizando como critério de seleção os títulos de interesse, além de bibliografia extraída de referências dos artigos estudados, trabalhos clássicos e dispositivos legais.

Pretendeu-se ensaiar a articulação de idéias e autores no espaço editorial acadêmico-científico, neste intentando destacar a possibilidade do esforço interdisciplinar. Apontamentos contextualizados aos aspectos da temática trânsito enquanto área de reflexão teórico pratica. A luz de abordagem, emergente em vários espaços de discussão, pesquisa, ensino e prática profissional, a saber: do paradigma "saudável", ou seja, para além do foco preventivo um entendimento num direcionamento para promoção da saúde individual e coletiva, entendido saúde em seu entendimento lato sensu e trânsito como questão não apenas de segurança pública. Um olhar ao sustentável, com foco numa gestão de atores, elementos e variáveis presentes no contexto do trânsito que favoreça um enfrentamento racional eficiente e eficaz e, portanto efetivo, diante dos agigantados desafios sociais. Como exposto a seguir.

\section{RESULTADOS E DISCUSSÃO}

Entendendo não ser suficiente apenas a definição do dicionário para classificarmos, conceituarmos ou mesmo percebermos o que significa o termo trânsito, nota-se que o sentido e significação da palavra quando técnico-cientifica, em grande medida são indicados pelos contextos, espaço ou a área do saber a qual a utiliza (VIARO, 2011).

Em um sentido amplo, o termo 'trânsito' pode extrapolar sua significação técnicocientífica, considerando o contexto em que é utilizado, tendo a ver com movimentos, relações e com a própria dinâmica inerente a vida. Trânsito é um fenômeno próprio da vida. $\mathrm{Na}$ fisiologia humana, ele acontece por meio da interação de nossos constituintes físicos, emocionais, sociais. Logo, está intimamente ligado ao movimento, que se faz ponto de interseção transversal comum a toda experiência humana, e torna este assunto uma realidade atemporal, parte de todas sociedades e culturas (HOFFMANN et al., 2003).

Neste trabalho, trânsito foi entendido como preconizado pela lei 9.503, de 23 de setembro, de 1997, que institui o Código de Trânsito Brasileiro (CTB), denominando trânsito 
"a utilização das vias por pessoas, veículos e animais, isolados ou em grupos, conduzidos ou não, para fins de circulação, parada, estacionamento e operação de carga ou descarga" (BRASIL, 2016a).

As questões sobre trânsito e sua organização têm ocupando a mente humana por conta das mudanças tecnológicas e da urbanização crescente dos últimos séculos. Já Leonardo da Vinci, no século $\mathrm{XVI}$, propusera uma resolução para o intenso tráfego de pedestres e carruagens, sugerindo o uso de um desnível nas laterais da via, definindo, assim, um espaço próprio para a circulação de pedestres, configurando elemento imprescindível da via, que hoje chamamos 'calçada' (SILVA, 2004; BRASIL, 2009; 1997).

O primeiro acidente com veículo automotor foi registrado na Inglaterra, em 1896; a primeira morte de uma vítima de ATT, por atropelamento de um automóvel, em 13 de setembro 1899, em Nova lorque. No Brasil, curiosamente, o primeiro a transitar de automóvel foi Santos Dumont, o 'pai da aviação', e o primeiro acidente de trânsito envolvendo um automotor registrado em 1987, com um veículo conduzido por José do Patrocínio que tinha como passageiro Olavo Bilac (HOFFMANN et al., 2003).

De lá para cá, os agravos, os riscos e as exposição às causas externas (acidentes e violências), bem como outras várias consequências, como traumas e traumatismos, aumentaram exponencialmente (FREITAS et al., 2015; MALTA et al. 2012; PEREIRA e LIMA 2006; MARIN, QUEIROZ, 2000)

\section{CONTEXTOS E ESPAÇOS DE REFLEXÃO TEÓRICO-PRÁTICA}

O ser humano busca descrever e explicar a realidade de modo de que este saber o beneficie de alguma maneira. Os espaços para formação acadêmica, científica e profissional (e não apenas os espaços físicos) se tornam propícios nesta busca (CIRANI et al., 2015; PAIVA, MELO, 2008) também na temática trânsito.

O trânsito, relacionado à circulação e à mobilidade humana, no meio acadêmico, assume diversos encaminhamentos. Em sentido estrito, relacionado à circulação e à mobilidade humana, é fenômeno estudado por áreas como Ciências Humanas e Sociais, Ciências Exatas e da Terra (BRASIL, 2014B; PAVARINO FILHO, 2009). No Brasil, no meio profissional tecnológico, foram recentemente regulamentados e divulgados vários cursos técnicos relacionados ao trânsito, classificados no eixo tecnológico de infraestrutura e mobilidade pelo Ministério da Educação, por meio do Programa Nacional de Acesso ao Ensino Técnico e Emprego (Pronatec) (BRASIL 2014B).

É, porém, ainda comedido o espaço acadêmico dedicado ao trânsito e a construtos similares, como tráfego humano, mobilidade urbana, segurança no trânsito, representados eventualmente no Ensino Superior brasileiro, por iniciativas isoladas (BRASIL, 2016b).

Em cursos de Pós-Graduação stricto sensu, segundo a Coordenação de Aperfeiçoamento e Pessoal do Ensino Superior (CAPES), as especializações nesta área 
ainda se dão de modo secundário. São, geralmente, linhas de pesquisa que refletem uma abordagem multidisciplinar de avaliação, que dialogam, em alguma medida, com as demandas relacionadas ao trânsito, mas que não ocupam primazia ou protagonismo nas dissertações e teses (BRASIL, 2016b).

Após breve consulta on-line na Plataforma Sucupira da CAPES, nenhum programa de Mestrado ou Doutorado com titulação que contivesse o termo 'trânsito' foi encontrado. O termo 'transportes' foi encontrado em oito programas de Mestrado e em cinco de Doutorado - todos ligados a Engenharia (BRASIL, 2016c).

É pequena expressão do trânsito como espaço temático no campo editorial acadêmico científico brasileiro, conforme o inexpressivo número de periódicos e publicações na área, e as poucas ocorrências em áreas tradicionais. Verifica-se a existência apenas da Revista Transportes com temática análoga.

Nas produções acadêmicas e científicas, propriamente nas Ciências da Saúde, o trânsito, como objeto de estudo da epidemiologia, da Psicologia e da saúde pública, tem sido frequentemente relacionado à morbimortalidade, com os ATT constituindo uma das principais causas de morte prematura no Brasil e no mundo. Assim o trânsito integra-se entre os temas prioritários da Política Nacional de Promoção da Saúde em sua edição (BRASIL, 2006) e redefinição (BRASIL, 2014C), caracterizado como problema de segurança pública (MALTA et al., 2014; BACCHIERI e BARROS, 2011; MARÍN et al., 2006).

Em uma análise sobre a mortalidade em jovens no período de 1930 a 1991, Vermelho e Jorge (1996, p. 329) destacam a transição epidemiológica para a violência, evidenciando o novo perfil de mortalidade atrelado aos acidentes de trânsito de veículo a motor. Eles destacam que, até 1950, a mortalidade elevada se dava predominantemente pelas as doenças infecciosas; a partir de 1960 "a transição se tornou evidente e as causas violentas passaram a ocupar a primeira posição". Algumas Doenças Crônicas Não Transmissíveis (DCNT) e a AIDS também são mencionadas dentro de um contexto epidemiológico.

Bacchieri e Barros (2011), ao avaliarem os acidentes de trânsito no Brasil em publicações no período 1998 e 2010, pontuaram, entre as várias mudanças ocorridas no cenário político e social, a instituição, no ano de 1997, do novo CTB, em substituição ao Condigo Nacional de Trânsito (CNT), de 1966, entre outras várias providencias legislativas em contraste há poucos resultados efetivos na queda de mortalidade. Entre as causas apontadas para os ATT, está a conjugação entre álcool e direção, e os pedestres são o grupo considerado vulnerável ao alto índice em acidentes com vítimas fatais. Acidentes com motocicletas, ainda que não fatais, estão no topo do ranking de vítimas (sublinhando que acidentes com ciclistas também tem alto subregistro) (CARVALHO, FREITAS, 2012; ANJOS et al., 2007; PINSKY, PARAVINO FILHO, 2007; ABREU et al., 2006). 


\section{INTERDISCIPLINARIDADE: POR UM TRÂNSITO SAUDÁVEL}

Ainda nos domínios do olhar reflexivo sobre o trânsito em espaços apropriados, sejam escolares, profissionalizantes ou acadêmicos, vários artigos têm abordado da premissa interdisciplinar diante dos desafios sociais impostos pelo transito a realidade humana, nas áreas assistenciais, na práxis, em suas formas de avaliação e sua gestão, como estratégia para ações efetivas (VIEIRA et al., 2010; QUEIROZ e OLIVEIRA, 2003, MARIN e QUEIROZ, 2000).

A interdisciplinaridade tem sido abordada como um instrumento transversal de compartilhamento do saber, em uma espécie de superação da exacerbada fragmentação do conhecimento, sem pretender anteceder a disciplinaridade (esta, na verdade, é condição de existência daquela). Assim vários autores têm buscado caracterizar o que seria essa tal interdisciplinaridade, e outros ainda defini-la, por vários caminhos metodológicos (PEDUZZI et al., 2013; POMBO, 2008; JAPIASSU, 1976).

Ainda que a explicitação de entendimento de um dado construto seja inclusive necessário e desejável ao rigor e comunicação técnica e cientifica (VIARO, 2011), alguns autores têm se alinhado ou se aproximado de uma abordagem deleuziana, que, diante de construtos nucleares, permite a indicação de uma opção, diante de uma multiplicidade criativa de entendimentos igualmente válidas ou aceitas, mantendo sempre uma corrente aberta ao novo evitando o caráter finalista da conceituação tradicional. Logo, aqui neste trabalho procuraremos brevemente mais caracterizar no que seja ou não a interdisciplinaridade do que propriamente defini-la (FAZENDA et al., 2014; FAZENDA, 2006; TAVARES, 2008; DELEUZE e GUATTARI, 1995).

Historicamente é inegável o mérito do paradigma cartesiano exatamente em ter originado alguns dos principais pressupostos do estatuto científico concebido em seus aspectos fundantes entre os séculos XVI a XVIII, representado entre outras obras pelo "Discurso do Método" de Rene Descartes, a partir da qual se originou alguns dos principais pressupostos do estatuto cientifico, como também do pensamento que ampliou uma busca pelo entendimento do objeto cientifico "das partes para o todo". Uma abordagem que tem sido entendida como importante a uma época conhecida como iluminismo, nome este dado como referência a uma reação a dita obscuridade racional, reinante na época (MORIN, 1996; CAPRA, 1998).

No entanto, são apontadas diversas limitações tanto nos pressupostos nos quais foram pensadas a abordagem (como expresso metáfora do relógio), e também nos próprios resultados e desdobramentos de conceber o conhecimento tido como fragmentado, não condizentes ao enfretamento efetivo das demandas do contexto atual, sendo mesmo em alguns pontos superados tais entendimentos por aqueles que tem buscado uma nova e racional maneira de habitar o espaço cientifico, profissional, social. Uma abordagem mais próxima da complexidade da realidade, onde o complexo representa uma integração destas mesmas partes que trazem a constituição de sua existência. (MORIN, 1996; CAPRA, 1998).

O esforço da prática interdisciplinar se daria, então, por ações que favoreçam o 
diálogo entre as disciplinas e, para além disso, uma transversalização do conhecimento, de modo tal que o produto desta interação seja não apenas de um dos componentes do grupo, mas resultado da coletividade, culminando em conhecimento, saber ou intervenção mais afetiva. Isto só é possível ao se aliar a competência técnica-cientifica à uma disposição aberta em relação a outros saberes. Tais entendimentos podem variar quando apresentados por autores distintos, dependendo de sua filiação teórica, sendo inclusive, a partir daí, postuladas novas linhas de pensamento, mas a tônica parece ser a de um novo e mais aprofundado olhar.

Deste modo, a interdisciplinaridade tem sido relevante instrumento na operacionalização de concepções alternativas e respostas mais apropriadas e eficazes em aplicações teóricas e práticas (FAZENDA, 2014; PEDUZZI et al., 2013). Trata-se de um espaço aberto a novas reflexões e aplicações, a partir da abordagem e do entendimento de um 'trânsito dito saudável', que extrapola o tradicional eixo preventivo, emergindo como força política e social articuladora de um novo e mais abrangente entendimento de saúde, como também extensível à temática trânsito e a seus desdobramentos, impactando no cotidiano e na práxis dos atores deste cenário.

Vale ressaltar dois documentos importantes na discussão sobre questões do trânsito suas prioridades, contradições e dilemas. O primeiro o relatório da Organização Mundial da Saúde - OMS (NORMAN, 1962) elaborado pelo médico Leslie G. Norman "Road traffic acidentes: epidemiology. control and prevention," que se deu como marco se tornando um dos relatórios mais importantes a época, inclusive por reconhecer formalmente a partir daquele ano o trânsito como uma questão de saúde pública.

Comentando a respeito Pavarino Filho (2009) identifica no documento a busca de uma metáfora entre termos comuns da epidemiologia e os componentes e atores essenciais no trânsito e da ênfase dada em relação aos acidentes de trânsito foi "particularmente no que se refere a velocidade e à direção sob o efeito de bebida alcoólica". Ênfase que tem sido dada em vários estudos sobre os efeitos do álcool combinado a direção. (MONTEIRO 2012; PINSKY, PARAVINO FILHO 2007; DUAILIBI. PINSKY, LARANJEIRA 2007; PINSKY, LABOUVIE, LARANJEIRA 2004)

O segundo documento foi um marco mundial e histórico. A OMS destacou, no ano de 2004, a "segurança no trânsito" como temática do World report on road traffic injury prevention, elevando a temática trânsito a plataforma de enfática visualização diante dos tremendos impactos não só da segurança e da saúde públicas, mas também da sustentabilidade ambiental e da vida humana (WHO, 2004)

Em seu artigo sobre a morbimortalidade no trânsito Pavarino Filho (2009) traz ainda a discussão para o contexto brasileiro evidenciando a transição social, política, econômica e estrutural diante das resoluções propostas no relatório de 1962, e as mudanças paradigmáticas já evidenciadas no relatório de 2004, ambos da OMS supracitados. Destacando questões como mobilidade, sustentabilidade e equidade nos transportes. Sugerindo a partir daí que o posto no relatório de 2004 se alinha aos pressupostos da promoção da saúde. Concluindo por trazer a sugestão o paradigma da promoção da saúde, 
visto como campo interdisciplinar, como uma possibilidade de superar as incoerências e conflitos no trânsito, e uma possível dicotomia entre educação e saúde para o trânsito. Sugerindo ainda como necessários novos e mais aprofundados estudos exploratórios deste relevante tema, inclusive dentre o emergente espaço acadêmico brasileiro em promoção da saúde. A promoção da saúde, entendida como campo interdisciplinar e contextualizada em uma realidade social e histórica, pode se dar não apenas como meio político articulador (LUZ, 2009; PEREIRA et al., 2000; CANDEIAS, 1997), mas também como estratégia para superar as fortes tensões presentes na temática trânsito, trazendo uma reflexão voltada com foco para além da prevenção de acidentes, assim orientada para ao que poderia ser entendido ou chamado de trânsito saudável: uma valorização da vida e da saúde através de uma estrutura congruente, ambientada a convivência e relação fraterna, mediados pelo trânsito como veículo de acesso e estreitamento das relações e laços humanos sejam estes físicos ou subjetivos, intencionando o bem estar e qualidade de vida social.

Para o entendimento de saudável, aqui, convém mobilizar a possível etimologia da palavra: uma variação do substantivo feminino saúde, que significa "estado de são", "salvação", de origem da palavra latina "salus-utis", remontando ao século XV (CUNHA, 2010). Isto converge de algum modo entre muitos autores, ainda que não em todos os pontos e nem sem discussão (MENDES et al., 2008; ALMEIDA-FILHO, 2000). Para Almeida Filho (2000, p. 300), a etimologia do termo saúde

\begin{abstract}
denota uma qualidade dos seres intactos, indenes, com sentido vinculado às propriedades de inteireza, totalidade. Em algumas vertentes, saúde indica solidez, firmeza, força. Por outro lado, as línguas ocidentais modernas desenvolveram uma variante distinta, com base em raiz etimológica medieval de base religiosa, vinculada às conotações de perfeição e santidade.
\end{abstract}

Há uma possível origem religiosa do termo. Sathler-Rosa (2014, p. 131) explicita que, em "hebraico bíblico, a etimologia da palavra shalem (saudável, inteiro) possui a mesma raiz que shalom (paz, inteiro ou íntegro, salvação)". 'Saudável', na literatura, pode ainda estar atrelado a hábitos de vida (BARROS et al., 2013), comportamentos (BOVA e WALL, 2005), estilo de vida (RODRIGUEZ-AÑEZ, 2008), sociedade (COSTA, 1997), políticas públicas (BUSS, 2000), municípios/cidades (WESTPHAL e MENDES, 2000) e, por fim, ao ambiente e ao trânsito (MINAYO e DESLANDES, 2009).

Parte dessas referências ao construto saudável estão atreladas as estratégias de promoção da saúde amplamente divulgadas pela Organização Mundial da Saúde, por iniciativas tais como as "cidades saudáveis". Uma via para uma gestão participativa e sustentável, como coloca Adriano et al. (2000, p. 54)

a proposta de construção de cidades saudáveis surgiu em Toronto, Canadá, em 1978, quando um comitê de planejamento publicou o informe A saúde pública nos anos 80 , onde foram estabelecidas linhas de ação política, social e de desenvolvimento comunitário no nível local.

O esforço na integração interdisciplinar e sustentável, que articule o coletivo, é uma alternativa para se implementar o saudável. Neste sentido, várias propostas e ações tem 
sido implementadas desde o lançamento da estratégia em várias frentes de trabalho no Brasil (BUSS, 2000, 2009). No entanto, existe um longo e largo caminho a ser trilhado, especialmente quando relacionada a temática trânsito a promoção da saúde, como já pontuado em alguma medida neste trabalho.

\section{CONSIDERAÇÕES FINAIS}

Os avanços são marcantes, mas ainda insuficientes, nas discussões sobre trânsito. O exercício interdisciplinar, nos meios acadêmico e cientifico, constitui alternativa saudável no enfrentamento dos desafios impostos pela modernidade e pela tecnologia. É também instrumento articulador, que favorece a produção de conhecimentos significativos e efetivos, fortalecendo a base empírica da literatura e sustentando uma plataforma da qual se possam eclodir projetos de extensão social, que ultrapassem os muros institucionais, conduzindo uma ponte para um trânsito de transversalização e integração social.

Novos caminhos para uma proposta integradora ainda devem ser trilhados, dadas as incipientes reflexões e discussões nos meios acadêmicos. Parecer haver até mesmo uma lacuna identitária no estudo das relações que dizem respeito à realidade e aos contextos em que se dá o trânsito, sugerindo a necessidade uma agenda de novos e mais aprofundados estudos das várias facetas relacionadas a temática trânsito.

\section{REFERÊNCIAS}

ABREU, A. M. M.; LIMA, J. M. B. O impacto do álcool na mortalidade em acidentes de trânsito: uma questão de saúde pública. Escola Anna Nery Revista de Enfermagem, v. 10, n. 1, pp. 87-94. 2006. Disponível em: <http://www.scielo.br/scielo.php?pid=S1414$81452006000100011 \&$ script=sci_abstract\&tlng=pt>. Acesso em: 20 jun. 2018.

ADRIANO, J. R. et al. A construção de cidades saudáveis: uma estratégia viável para a melhoria da qualidade de vida. Ciência \& Saúde Coletiva, v. 5, n. 1, p. 53-62, 2000. Disponível em: <http://www.scielo.br/scielo.php?pid=S1413$81232000000100006 \&$ script=sci_abstract\&tIng=pt>. Acesso em: 20 jun. 2018.

ALMEIDA FILHO, N. Qual o sentido do termo saúde?. Cadernos de Saúde Pública, v. 16, n. 2, p. 300-301, 2000. Disponível em:

<http://www.scielo.br/scielo.php?script=sci_arttext\&pid=S0102-311X2000000200001>. Acesso em: 20 jun. 2018.

ANJOS, K. C. et al. Paciente vítima de violência no trânsito: análise do perfil socioeconômico, características do acidente e intervenção do Serviço Social na emergência. Acta Ortopédica Brasileira, v. 15, n. 5, pp. 262-266. 2007. Disponível em: $<$ http://www.scielo.br/scielo.php?pid=S1413-

78522007000500006\&script=sci_abstract\&tlng=pt>. Acesso em: 20 jun. 2018.

AZEVEDO, E.; PELICIONI, M. C. F.; WESTPHAL, M. F. Práticas intersetoriais nas 
políticas. Physis Revista de Saúde Coletiva, v. 22, n. 4, p. 1333-1356, 2012. Disponível em: <http://www.scielo.br/pdf/physis/v22n4/a05v22n4.pdf>. Acesso em: 20 jun. 2018.

BACCHIERI, G.; BARROS, A. J. D. Acidentes de trânsito no Brasil de 1998 a 2010: muitas mudanças e poucos resultados. Revista de Saúde Pública, v. 45, n. 5, p. 949963, 2011. Disponível em: <http://www.scielo.br/scielo.php?pid=S0034$89102011000500017 \&$ script=sci_abstract\&tIng=pt>. Acesso em: 20 jun. 2018.

BARROS, C. R. et al. Implementação de programa estruturado de hábitos de vida saudáveis para redução de risco cardiometabólico. Arquivos Brasileiros de Endocrinologia e Metabologia, v. 57, n. 1, p. 7-18, 2013. Disponível em: $<$ http://www.scielo.br/scielo.php?pid=S0004$27302013000100002 \&$ script=sci_abstract\&tlng=pt>. Acesso em: 20 jun. 2018.

BOVA, V. B. R.; WALL, M. L. Educação em saúde no trânsito: uma contribuição da enfermagem. Cogitare Enfermagem, v. 10, n. 1, p. 60-65, 2005. Disponível em: <https://revistas.ufpr.br/cogitare/article/view/4676>. Acesso em: 20 jun. 2018.

BRASIL. Ministério da Educação. Plataforma Sucupira. Brasília, DF: Ministério da Educação, 2016. Disponível em: <https://sucupira.capes.gov.br>. Acesso em: 20 jun. 2018.

BRASIL. Ministério das Cidades. Departamento Nacional de Trânsito. Resolução 514, de 18 de dezembro de 2014. Brasília, DF: Ministério das Cidades, 2014A.

BRASIL. Ministério da Educação. Secretaria e Educação Profissional e Tecnológica. Diretoria de Políticas de Educação Profissional e Tecnológica. Catálogo Nacional de Cursos Técnicos. Brasília, DF: Ministério da Educação, 2014B. Disponível em: <http://portal.mec.gov.br/catalogo-nacional-de-cursos-tecnicos>. Acesso em: 20 jun. 2018.

BRASIL. Ministério da Saúde. Portaria no 2.446, de 11 de novembro de 2014. Brasília, DF: Ministério da Saúde, 2014C. Disponível em: <http://bvsms.saude.gov.br/bvs/saudelegis/gm/2014/prt2446_11_11_2014.html>. Acesso em: 20 jun. 2018.

BRASIL. Ministério das Cidades. Denatran. Projeto Capacitação de Profissionais de Trânsito: Legislação de Trânsito. Brasília, DF: Ministério das Cidades, 2009.

BRASIL. Ministério da Saúde. Secretaria de Vigilância em Saúde. Secretaria de atenção à Saúde. Política Nacional de Promoção da Saúde. 3. ed. Brasília, DF: Ministério da Saúde, 2006. Série B. Textos Básicos de Saúde. Série Pactos pela Saúde 2006, v. 7. Disponível em:

<http://bvsms.saude.gov.br/bvs/publicacoes/politica_nacional_promocao_saude_3ed.pdf>. Acesso em: 20 jun. 2018.

BRASIL. Ministério da Saúde. Secretaria de Políticas de Saúde. Projeto Promoção da Saúde. Programa de redução da morbimortalidade por acidentes de trânsito.

Mobilizando a sociedade e promovendo a saúde. Brasília, DF: Ministério da Saúde, 2002. Série C. Projetos, Programas e Relatórios. Disponível em: $<$ http://bvsms.saude.gov.br/bvs/publicacoes/prog_reducao_acidentes.pdf>. Acesso em: 20 jun. 2018. 
BRASIL. Presidência da República. Casa Civil. Lei nº 9.503, de 23 de setembro de 1997. Brasília, DF: Casa Civil; 1997 Disponível em:

<http://www.planalto.gov.br/ccivil_03/leis/L9503Compilado.htm>. Acesso em: 20 jun.

2018.

BRASIL. Ministério da Educação. Coordenação de Aperfeiçoamento e Pessoal do Ensino Superior - CAPES. Brasília, DF: Ministério da Educação, s/d. Disponível em: <www.capes.gov.br>. Acesso em: 20 jun. 2018.

BUSS, P. M. Promoção da saúde e qualidade de vida. Ciência \& Saúde Coletiva, v. 5, n. 1, p.163-177, 2000

BUSS, P. M.CARVALHO, A. I. Desenvolvimento da promoção da saúde no Brasil nos últimos vinte anos (1988-2008). Ciência \& Saúde Coletiva, v. 14, n. 6, p. 2305-2316, 2009.

CANDEIAS, N. M. F. Conceitos de educação e de promoção em saúde: mudanças individuais e mudanças organizacionais. Revista de Saúde Publica, v. 31, n. 2: p. 209213, 1997. Disponível em: <http://www.scielo.br/scielo.php?pid=S0034-

89101997000200016\&script=sci_abstract\&tlng=pt>. Acesso em: 20 jun. 2018.

CAPRA, F. O Ponto de Mutação. São Paulo: Cultrix, 1998.

CARVALHO, M. L.; FREITAS, C. M. Pedalando em busca de alternativas saudáveis e sustentáveis. Ciência \& Saúde Coletiva, v. 17, n. 6, pp. 1617-1628. 2012. Disponível em: <http://www.scielo.br/scielo.php?pid=S1413-

$81232012000600024 \&$ script=sci_abstract\&tlng=pt>. Acesso em: 20 jun. 2018.

CIRANI, C. B. S.; CAMPANARIO, M. A.; SILVA, H. H. M. A evolução do ensino da pósgraduação senso estrito no Brasil: análise exploratória e proposições para pesquisa. Avaliação: Revista da Avaliação da Educação Superior (Campinas), v. 20, n. 1, p. 163-187, 2015. Disponível em: <http://www.scielo.br/scielo.php?pid=S141440772015000100163\&script=sci_abstract\&tIng=pt>. Acesso em: 20 jun. 2018.

COSTA, J. L. R. Algumas reflexões sobre cidade saudável. Saúde e Sociedade, v. 6, n. 2, p. 65-70, 1997. Disponível em:

<http://www.scielo.br/scielo.php?script=sci_arttext\&pid=S0104-12901997000200008>. Acesso em: 20 jun. 2018.

COSTA, M. S. Mobilidade urbana sustentável: um estudo comparativo e as bases de um sistema de gestão para Brasil e Portugal. Tese [Doutorado]. São Paulo: USP, 2003.

CUNHA, A. G. Dicionário etimológico Nova Fronteira da língua portuguesa. Rio de Janeiro: Nova Fronteira, 2010.

DELEUZE, G.; GUATTARI, F. Mil platôs - capitalismo e esquizofrenia. Tradução de Aurélio Guerra Neto e Célia Pinto Costa. Rio de Janeiro: Ed. 34, 1995. Volume 1.

DUAILIBI, S.; PINSKY, I.; LARANJEIRA, R. Prevalência do beber e dirigir em Diadema, estado de São Paulo. Revista de Saúde Pública. 2007, v. 41, n. 6, pp. 1058-

1061. Disponível em: <http://www.scielo.br/scielo.php?script=sci_abstract\&pid=S0034$89102006005000045 \&$ lng=pt\&nrm=iso\&tlng=pt>. Acesso em: 20 jun. 2018. 
FAZENDA, I. C. A. Interdisciplinaridade: história, teoria e pesquisa. São Paulo: Papirus, 2006.

FAZENDA, I. C. A.; VARELLA, A. M. R. S.; ALMEIDA, T. T. O. Interdisciplinaridade: tempo, espaços, proposições. Revista Científica e-Curriculum, v. 11, n. 3, p. 847-862, 2014. Disponível em: <https://revistas.pucsp.br/index.php/curriculum/article/view/14914>. Acesso em: 20 jun. 2018.

FREITAS, M. G. et al. Idosos atendidos em serviços de urgência no Brasil: um estudo para vítimas de quedas e de acidentes de trânsito. Ciência e Saúde Coletiva. v. 20, n. 3, pp. 701-712. 2015. Disponível em:

<http://www.scielo.br/pdf/csc/v20n3/pt_1413-8123-csc-20-03-00701.pdf>. Acesso em: 20 jun. 2018.

HADDAD, A. E. et al. Formação de profissionais de saúde no Brasil: uma análise no período de 1991 a 2008. Revista de Saúde Pública, v. 44, n. 3, p. 383-93, 2010. Disponível em: <http://www.scielo.br/scielo.php?script=sci_arttext\&pid=S003489102010000300001 >. Acesso em: 20 jun. 2018.

HOFFMANN, M. H.; CRUZ, R. M.; ALCHIERI, J. C. Comportamento Humano no Trânsito. São Paulo: Casa do Psicólogo, 2003.

JAPIASSU, H. Interdisciplinaridade e patologia do saber. Rio de Janeiro: Imago, 1976.

LUZ, M. T. Complexidade do campo da saúde coletiva: multidisciplinaridade, interdisciplinaridade e transdisciplinaridade de saberes e práticas - análise sócio-histórica de uma trajetória paradigmática. Saúde e Sociedade. São Paulo, v. 18, n. 2, p. 304-11, 2009. Disponível em: <http://www.scielo.br/scielo.php?pid=S0104$12902009000200013 \&$ script=sci_abstract\&tlng=pt>. Acesso em: 20 jun. 2018.

MASSAÚ, G. C.; ROSA, R. G.. Acidentes de trânsito e direito à saúde: prevenção de vidas e economia pública. Revista de Direito Sanitário, v. 17, n. 2, p. 30-47, 2016.

MALTA, D. C. et al. Causas externas em adolescentes: atendimentos em serviços sentinelas de urgência e emergência nas Capitais Brasileiras - 2009. Ciências e Saúde Coletiva, v. 7, n. 9, pp. 2291-2304, 2012. Disponível em: <http://www.scielo.br/pdf/csc/v17n9/a11v17n9.pdf>. Acesso em: 20 jun. 2018.

MARCONI, M. A.; PRESOTTO, Z. M. N. Antropologia: uma introdução. 3. ed. São Paulo. Atlas, 1986.

MARIN-LEON, L.; VIZZOTTO, M. M. Comportamentos no trânsito: um estudo epidemiológico com estudantes universitários. Cadernos de Saúde Pública, v. 19, n. 2, pp. 515-523, 2003. Disponível em: <http://www.scielo.br/scielo.php?pid=S0102311X2003000200018\&script=sci_abstract\&tlng=pt>. Acesso em: 20 jun. 2018.

MARIN, L.; QUEIROZ, M. S. A atualidade dos acidentes de trânsito na era da velocidade: uma visão geral. Cad. Saúde Pública, Rio de Janeiro, v. 16, n. 1, p. 7-21, jan-mar, 2000.

MARTINS, R. C. M. Crimes culposos de trânsito. São Paulo, 2010. 191f. Dissertação (Mestrado em Direito) - Pontifícia Universidade Católica de São Paulo, São Paulo, 2010. 
MENDES, J. M. R.; LEWGOY, A. M. B.; SILVEIRA, E. C. Saúde e interdisciplinaridade: mundo vasto mundo. Ciência \& Saúde, v. 1, n. 1, p. 24-32, 2008. Disponível em: $<$ http://revistaseletronicas.pucrs.br/ojs/index.php/faenfi/article/view/3864>. Acesso em: 20 jun. 2018.

MINAYO, M. C. S. Morre menos quem morre no trânsito? Ciência \& Saúde Coletiva, v. 17, n. 9, pp. 2237-2245. 2012. Disponível em:

<http://www.cienciaesaudecoletiva.com.br/artigos/morre-menos-quem-morre-notransito/10710?id=10710 >. Acesso em: 20 jun. 2018.

MINAYO, M. C. S.; DESLANDES, S. F. Análise da implantação da rede de atenção às vítimas de acidentes e violências segundo diretrizes da Política Nacional de Redução da Morbimortalidade sobre Violência e Saúde. Revista Ciência \& Saúde Coletiva, v. 14, n. 5, pp.1641-1649, 2009. Disponível em:

<http://www.scielo.br/scielo.php?script=sci_arttext\&pid=S1413-81232009000500002>. Acesso em: 20 jun. 2018.

MODERNELL, R. Cinco mil anos de loucuras no trânsito. Revista Quatro Rodas, p.4449, 1989.

MORIN, E. Ciência com consciência. Rio de Janeiro: Bertrand Brasil, 1996.

MONTEIRO, V. B. P. N. Uso de álcool, comportamentos de risco no trânsito e habilidades sociais em universitários. Marilia, 2012. 60f. Dissertação (Mestrado em Educação) Universidade Estadual Paulista “Júlio de Mesquita Filho, Marilia, 2012.

NORMAN, L. G. Road traffic accidents: epidemiology, control, and prevention. Geneva: Word Health Organization, 1962. Disponível em:

<http://apps.who.int/iris/handle/10665/39723>. Acesso em: 20 jun. 2018.

PACKER, A. (org). SciELO - 15 Anos de Acesso Aberto: um estudo analítico sobre Acesso Aberto e comunicação científica. Paris: UNESCO, 2014.

PAIVA, K. C. M.; MELO, M. C. O. L. Competências, Gestão de Competências e Profissões: Perspectivas de Pesquisas. Revista de Administração Contemporânea, v. 12, n. 2, p. 339, 2008. Disponível em: <http://www.scielo.br/pdf/rac/v12n2/a04v12n2.pdf>. Acesso em: 20 jun. 2018.

PAVARINO FILHO, R. V. Morbimortalidade no trânsito: limitações dos processos educativos e contribuições do paradigma da promoção da saúde ao contexto brasileiro. Epidemiologia e Serviços de Saúde, v.18, n.4, pp. 375-384. 2009. Disponível em: <http://scielo.iec.gov.br/scielo.php?script=sci_arttext\&pid=S1679-49742009000400007>. Acesso em: 20 jun. 2018.

PEDUZZI, M. et al. Educação interprofissional: formação de profissionais de saúde para o trabalho em equipe com foco nos usuários. Revista da Escola de Enfermagem da USP, v. 47, n. 4, p. 977-983, 2013. Disponível em:

<http://www.scielo.br/scielo.php?script=sci_abstract\&pid=S0080-

62342013000400977\&lng=pt\&nrm=iso\&tlng=en >. Acesso em: 20 jun. 2018.

PEREIRA, I. M. T.; PENTEADO, R. Z.; MARCELO, V. C. Promoção da Saúde e Educação em Saúde: uma parceria saudável. O Mundo da Saúde. São Paulo, v. 24, n. 1, p.39-44, 
2000.

PEREIRA, W. A. P.; LIMA, M. A. D. S. Atendimento pré-hospitalar: caracterização das ocorrências de acidente de trânsito. Acta Paul Enferm. v. 19, n. 3, p. 279-83, 2006.

PINSKY, I.; LABOUVIE, E.; LARANJEIRA, R. Disposição e alternativas ao dirigir alcoolizado entre jovens paulistanos. Revista Brasileira de Psiquiatria, v. 26, n. 4, pp. 234-241. 2004. Disponível em:

<http://www.scielo.br/scielo.php?script=sci_abstract\&pid=S1516-

$44462004000400006 \&$ Ing=pt\&nrm=iso>. Acesso em: 20 jun. 2018.

PINSKY, I.; PAVARINO FILHO, R. V. A apologia do consumo de bebidas alcoólicas e da velocidade no trânsito no Brasil: considerações sobre a propaganda de dois problemas de saúde pública. Revista de Psiquiatria do Rio Grande do Sul, v. 29, n. 1, pp. 110-118. 2007. Disponível em: <http://www.scielo.br/scielo.php?pid=S0101-

81082007000100019\&script=sci_abstract\&tIng=pt>. Acesso em: 20 jun. 2018.

POMBO, O. Epistemologia da interdisciplinaridade. Revista Ideação, v. 10, n 1, p. 9-40, 2008. Disponível em: <http://e-revista.unioeste.br/index.php/ideacao/article/view/4141>. Acesso em: 20 jun. 2018.

PUCCINI, L. R. S. et al. Comparativo entre as bases de dados PubMed, SciELO e Google Acadêmico com o foco na temática Educação Médica. Cadernos UniFOA, n. 28, p. 7582, 2015.

QUEIROZ, M. S.; OLIVEIRA, P. C. P. Acidentes de trânsito: uma análise a partir da perspectiva das vítimas em Campinas. Psicologia \& Sociedade. v. 15, n. 2, pp. 101 123. 2003. Disponível em: <http://www.scielo.br/scielo.php?pid=S0102$71822003000200008 \&$ script=sci_abstract\&tlng=pt>. Acesso em: 20 jun. 2018.

REICHENHEIM, M.E. et al. Violence and injuries in Brazil: the effect, progress made, and challenges ahead. Lancet, v. 377, n. 9781, p. 1962-1975, 2011. Disponível em: <https://www.researchgate.net/publication/51116591_Violence_and_injuries_in_Brazil_Th e_effect_progress_made_and_challenges_ahead>. Acesso em: 20 jun. 2018.

RODRIGUEZ-ANEZ C.R; REIS R.S; PETROSKI E.L. Versão brasileira do questionário Estilo de Vida Fantástico: tradução e validação para adultos jovens. Arq. Bras. Cardiol. [Internet]. 2008;91(2):102-9 [Acesso 11 out 2016]. Disponível em: http://www.scielo.br/scielo.php?script=sci_arttext\&pid=S0066-

782X2008001400006\&lng=pt\&nrm=iso\&tIng=pt. doi: http://dx.doi.org/10.1590/S0066 $782 \times 2008001400006$.

ROTHER, E. T. EDITORIAL Revisão sistemática x revisão narrativa. Acta Paulista de Enfermagem, v 20, n. 2, p. vi, 2007.

SATHLER-ROSA, R. Cuidado espiritual como fator de integralidade (saúde) do Ser: funções históricas do cuidado na tradição judaico-cristã. Revista Pistis \& Praxis, Teologia Pastoral, v. 6, n. 1, pp. 127-144, 2014. Disponível em: <https://periodicos.pucpr.br/index.php/pistispraxis/article/view/13058/12485>. Acesso em: 20 jun. 2018.

SILVA, F. H. V. C.; GÜNTHER, H. Psicologia do trânsito no Brasil: de onde veio e para 
onde caminha? Temas em Psicologia, v. 17, n.1, p. 163-175, 2009. Disponível em: <http://pepsic.bvsalud.org/scielo.php?script=sci_arttext\&pid=S1413389X2009000100014>. Acesso em: 20 jun. 2018.

SILVA, G. J. C.; MENEZES, L. B.; NEDER, H. D. Qualidade da malha rodoviária, custos econômicos associados e determinantes dos acidentes de trânsito no Brasil: avaliação e proposição de política. Revista de Políticas Públicas, v. 19, n. 1, p. 327-347, 2015. Disponível em:

<http://www.periodicoseletronicos.ufma.br/index.php/rppublica/article/view/4819>. Acesso em: 20 jun. 2018.

SOARES, D. P.; THIELEN, I. P. Projeto transformando o trânsito e a perspectiva do facilitador. Psicologia: Ciência e Profissão, v. 32, n. 3, p. 730-743, 2012. Disponível em: $<$ http://www.scielo.br/scielo.php?pid=S1414-

98932012000300016\&script=sci_abstract\&tlng=pt>. Acesso em: 20 jun. 2018.

SOUZA, A. C.; OLIVEIRA, I. M.; MARTINS, L. T. Promoção da saúde: espaço interdisciplinar para o estudo do estilo de vida. EFDesportes, v. 218, p. 1-4, 2016. Disponível em: <http://www.efdeportes.com/efd218/promocao-da-saude-espacointerdisciplinar.htm>. Acesso em: 20 jun. 2018.

TAVARES, D. E. A interdisciplinaridade na contemporaneidade: qual o sentido?. In FAZENDA, I. C. A. (org.). O que é interdisciplinaridade. São Paulo: Cortez, 2008.

VERMELHO, L. L.; JORGE, M. H. P. M. Mortalidade de jovens: análise do período de 1930 a 1991 (a transição epidemiológica para a violência). Revista de Saúde Pública, v. 30, n. 4, p. 319-331, 1996. Disponível em: <http://www.scielo.br/scielo.php?pid=S003489101996000400005\&script=sci_abstract\&tlng=pt>. Acesso em: 20 jun. 2018.

VERONESE, A. M.; OLIVEIRA, D. L. L. C. Os riscos dos acidentes de trânsito na perspectiva dos moto-boys: subsídios para a promoção da saúde. Cadernos de Saúde Pública, v. 22, n. 12, pp. 2717-2721, 2006. Disponível em: $<$ http://www.scielo.br/scielo.php?script=sci_abstract\&pid=S0102$311 X 2006001200021 \& \operatorname{lng}=$ en\&nrm=iso\&tlng=pt>. Acesso em: 20 jun. 2018.

VIARO, M. E. Etimologia. São Paulo: Contexto, 2011.

VIEIRA, L. J. E. S. et al. Relatos da equipe de saúde quanto às práticas educativas ao vitimado no trânsito durante a hospitalização/reabilitação num hospital de emergência. Saúde e Sociedade, v. 19, n. 1, pp. 213-223, 2010. Disponível em: $<$ http://www.scielo.br/scielo.php?pid=S010412902010000100018\&script=sci_abstract\&tlng=pt>. Acesso em: 20 jun. 2018.

VOSGERAU, D. S. A. R.; ROMANOWSKI, J. P. Estudos de revisão: implicações conceituais e metodológicas. Revista Diálogo Educacional, v. 14, n. 41, p. 165-189, 2014.

WORLD HEALTH ORGANIZATION (WHO). World report on road traffic injury prevention. Geneva: WHO, 2004.

WESTPHAL, M. F.; MENDES, R. Cidade saudável: uma experiência de interdisciplinaridade e intersetorialidade. Revista de Administração Pública, v. 34, n. 6, 
p. 47-61, 2000. Disponível em:

$<$ http://bibliotecadigital.fgv.br/ojs/index.php/rap/article/view/6347>. Acesso em: 20 jun. 2018. 